QUADERNS DE FILOSOFIA VOL. VII NÚM. I (2020): I I-I 3

eISSN: $234 \mathrm{I}-3042$

\title{
Temps estrany
}

$\mathrm{E}$ STEM VIVINT, i sobretot hem viscut, un temps estrany. No ens imaginàvem que hauríem d'experimentar allò que, durant més de dos mesos ja quan escrivim aquest text, ha sigut el nostre viure quotidià. Ni tan sols ho podíem imaginar quan vèiem persones en un lloc tan llunyà com la Xina eixir de casa a penes per anar a comprar i alguna, poca, cosa més, amb mascaretes cobrint-los el rostre, i vèiem equips de neteja i desinfecció amb vestits extravagants i tots els endergues necessaris per a la seua autoprotecció. Ho vèiem com qui veu una pel.lícula de ciència ficció. Un ambient gris, que imaginàvem fred i humit, però sobretot llunyà, no sols en l'espai, sinó més que res en la possibilitat. A poc a poc, d'un dia a l'altre començàrem a intuir, sense voler ni acabar-ho de creure, que la nostra vida normal, ordinària i còmoda es veuria somoguda i començaria a assemblar-se a aquelles imatges que no coneixíem més que pel televisor.

I seguiren dies estranys, dies de noves activitats que aviat esdevingueren costums nous. Tancats a casa, el món de fora era percebut com hostil, amenaçant. En els millors dels casos, fora, i no dins, estava el perill, els contagis, els morts. La casa era el refugi, la closca, l'embolcall protector. Dins de casa, els nostres, part dels nostres almenys (si havíem tingut sort). I el que pensàvem que només passava als altres, com aquelles imatges surrealistes que havíem vist a la televisió, començava a passar-nos també. I ja no era tan estrany, podia ser igual de terrible, però ja no tenia aquella boira que té l'inusual. La boira, quan t'envolta, et deixa veure el que tens a prop, $\mathrm{i}$ ara tot allò ja era ben pròxim, una nova quotidianitat. I veies que la malaltia i la mort no pertanyien només als mons del televisor, als altres, als éssers llunyans. Era a tocar i et podia tocar a tu perfectament.

Encetàrem noves dinàmiques, noves maneres d'organitzar el temps i les activitats. Si havies tingut eixa sort, tenies tot el temps del món per compartirlo amb els teus. Els fills podien gaudir dels seus pares tot el dia i patir-los també a estones; es feien coses en comú que no se solien fer. S'aprenien coses noves, es reprenien aficions oblidades o sempre ajornades. Havíem de conviure més que mai i en moments que no solíem compartir, i allò va generar 
noves maneres. I per omplir aquell temps nou desacostumat s'incrementà la creativitat: tothom era un creador, algú que tenia una habilitat, un talent que fins i tot a ell li era desconegut.

I es trobaven a faltar moltes coses, coses que ni sospitàvem que trobaríem a faltar: perquè mai no hauríem pensat que en seríem privats o perquè per comunes no sabíem valorar. De sobte, coses petites, gestos petits, actes quotidians, rutines menystingudes cobraven un valor mai no albirat. I ens prometérem que a partir d'ara les valoraríem com cal, tot sospitant, però, que quan passara la tronada ens n'oblidaríem, com oblidem el paraigua quan ja no plou. I férem mil propòsits, $\mathrm{i}$ ens prometérem més empatia i solidaritat. També ens enutjàrem com abans no ho havíem fet amb els qui no mostraven el compromís necessari, la solidaritat requerida. Canviàrem el nostre rànquing de professions lloables i de coses amb utilitat real. Deploràrem com mai que certs polítics tingueren trastocades les prioritats, que hagueren fet malbé o perjudicat el que aquesta desgràcia ens mostrava com a absolutament prioritari i essencial. Maleíem que s'haguera retallat allà on menys es podia retallar; que hagueren venut i posat en mans privades el que era de tots $i$ ha de ser de tots per sempre i sense escatimar. Se'ns mostrava amb tota la contundència quin ha de ser el valor de la política i de l'estat. Que la res publica no ha d'estar a disposició d'interessos privats.

De sobte somiàvem amb viure més a prop de la natura, més harmònicament amb el nostre ecosistema d'animals. Miràvem amb certa enveja aquella societat rural, on el veïnatge és molt més real i protector, on es pot comptar més facilment amb els altres per cobrir les necessitats puntuals. Les ciutats tenien els hospitals; els pobles petits tenien la cura de la fraternitat. De sobte, la fruita i la verdura, l'accés directe al menjar, podien semblar més valuosos que el cotxe nou que no podíem emprar.

Nosaltres, els docents i filòsofs, els socis de la Societat de Filosofia del País Valencià tinguérem també els nostres canvis particulars. Haguérem d'aprendre a fer classe des de casa, sense aquell contacte que consideràvem absolutament imprescindible i sense el qual no imaginàvem que ens poguérem explicar. Haguérem d'aprendre tècniques noves, improvisar recursos i mitjans; explicar-nos d'altres maneres. Mantenir el contacte sense tacte, moltes vegades ni tan sols visual. I ha estat un aprenentatge, un canvi i, com alguns diuen, una oportunitat. Hem hagut d'aprendre també a reunir-nos virtualment, online, per videoconferència, paraules noves per a una cosa nova, i hem trobat que no tot en això eren inconvenients, sinó que també tenia els seus avantatges, com, per exemple, haver d'esperar el torn per a parlar i no parlar més d'un alhora. Reunió virtual, què curiós, tots junts i cadascun a un lloc diferent: junts i a distància. Però haguérem de suprimir xarrades, haguérem d'ajornar el nostre 
congrés, que esperem que puguem realitzar efectivament en les noves dates previstes i al lloc previst: del 10 al 12 de setembre a la Facultat de Filosofia i Ciències de l'Educació de la Universitat de València. Tant de bo siga així, seria també un bon senyal.

Per dramàtica que resulte la cosa, hem sigut afortunats si ho comparem amb altres epidèmies (la majoria) de la història. La letalitat d'aquesta està (per ara i esperem que per sempre) molt per sota de la de la majoria de n'hi ha hagut. Hem comptat amb un sistema sanitari que, encara com i malgrat tot, encara tenia molta capacitat de funcionament $\mathrm{i}$ ens podia atendre en cas de necessitat com cap dels nostres antecessors n'havia disposat mai. D'altra banda, tenim uns mitjans tècnics que han permès que continuaren moltes activitats que fins no fa molt hauria estat impensable que es pogueren dur a terme en aquestes circumstàncies. Hem pogut estar en contacte, fer coses a distància, parlar-nos, veure'ns, cooperar, fer moltes coses junts sense estar al costat. I això que ara ens sembla quasi obvi hauria estat concebut com alguna cosa més que un miracle no fa tants anys.

I passarà, açò passarà com tot passa, però encara no ha passat. Hem d'estar encara alerta, perquè quede definitivament enrere el malson. Que no siga només un despertar a mitjanit per tornar-nos a adormir i tornar al malson. No coneixem encara quina és la natura real d'aquest perill, ni tenim encara la manera de deslliurar-nos-en. Convé, doncs, anar amb cura, no relaxar-nos abans d'hora. Però potser el millor que podem fer, el millor aprenentatge que podem extraure d'aquest temps estrany és que allò que ens prometérem en els moments de més preocupació, allò que aprenguérem i que ens va fer canviar les nostres valoracions no caiga en l'oblit a penes cesse la tronada i aparega el primer raig de sol. 